\title{
Low long-lasting insecticide nets (LLINs) use among household members for protection against mosquito bite in kersa, Eastern Ethiopia
}

\author{
Tesfaye Gobena ${ }^{1 * \dagger}$, Yemane Berhane ${ }^{2 \dagger}$ and Alemayehu Worku ${ }^{3 \dagger}$
}

\begin{abstract}
Background: In Ethiopia, despite the increasing availability of long-lasting insecticide treated nets (LLINs), the LLINs use among LLINs owning households has not been satisfactory. Identifying the circumstances and the associated factors is necessary to achieve the Millennium Development Goal targets. We aimed to assess barriers related with LLIN use at the household level.
\end{abstract}

Methods: A cross sectional survey was conducted in Kersa Demographic Surveillance and Health Research Center (KDS-HRC) from October to November 2010. A total of 2867 households were selected from a surveillance database using a simple random sampling technique. The data were collected by interviewing women, direct observation of LLINs conditions and use, and in-depth interviewing of key informants. Multivariate analysis was used to determine independent predictors of LLIN non-use.

Results: Of the total surveyed households, 65.5\% (1879) had at least one LLIN, but 33.5\% (630) LLINs owned households had used at least one LLIN the night before the survey. Low educational level of women, low awareness on malaria prevention, unavailability of separate sleeping room, LLIN colour preference, and unavailability of enough LLINs to the household members were the main barriers to LLIN use. A supplementary qualitative interview with key informants also identified that poor condition of LLINs; undermining the extent of malaria; and using the LLIN for other purposes as the main reasons for non-use.

Conclusions: This study indicates that only about one third of LLIN owned households are actually using at least one LLIN for protection against mosquito bite. Thus, majority of the residents are at higher risk of mosquito bite and acquiring of malaria infection. Households living in fringe zone are not benefiting from the LLIN protection. Further progress in malaria prevention can be achieved by specifically targeting populations in fringe zones and conducting focused public education to increase LLIN use.

\section{Background}

The use of insecticide-treated nets (ITNs) is one of the main malaria control strategies in most malaria endemic countries to reach the Roll Back Malaria (RBM) targets to reduce the malaria burden by $50 \%$ in 2010 compared to 2000 levels and at least $75 \%$ by 2015 [1]. Despite the large scale distribution of ITNs in many malaria endemic countries, there is a wide variation in the availability [2] and use of ITNs/LLINs at the household level [3-6].

\footnotetext{
* Correspondence: tesfayegobena@yahoo.com

${ }^{\dagger}$ Equal contributors

${ }^{1}$ College of Health Sciences, Haramaya University, Harar, P.O. Box: 235, Ethiopia

Full list of author information is available at the end of the article
}

In Ethiopia, the Ministry of Health $(\mathrm{MOH})$ conducted continuously mass distribution of LLINs between 2005 and 2007, targeting to distribute two LLINs per household in malaria endemic areas [7]. In these years, households LLIN ownership increased from 3.4\% to 53.3\%; while use among children under-five years of age and pregnant women increased from $1.5 \%$ and $1.1 \%$ to $33.1 \%$ and $35.2 \%$, respectively $[8,9]$.

Empirical evidence has demonstrated the effectiveness of LLINs in sub-Saharan Africa [10,11], though actual LLIN use remains unsatisfactory [12]. There are individual, household, ITN and environmental related barriers to bednet use among ITN/LLIN owning households. Low perception of malaria resulted in the decrease of

\section{Biomed Central}


motivation of consistent mosquito net use [13]; ITN use compliance decreased during the dry season [14]. Also types of ITNs and their poor conditions [6]; beliefs and perceptions of the cause of malaria [15]; low number of ITNs [16]; and demographic characteristics [15] were barriers to mosquito net use. A recent article also mentioned that hot weather, social factors, perceived low mosquito density, technical factors such as hanging of ITNs and its inadequate availability were the major reasons to non-use of mosquito nets among net owners [17].

In order to meet the Millennium Development Goals and the Roll Back Malaria targets, it is indispensable to determine the actual levels of use and to take timely corrective actions. Thus, the objective of the study was to determine the level of LLIN use and identify barriers of their use at the household level.

\section{Methods}

\section{Study setting}

The study was conducted in Kersa Demographic Surveillance and Health Research Center (KDS-HRC) of Kersa district in the eastern part of Ethiopia during the high malaria transmission season, October to November 2010 [18]. The altitude of the district ranges from 1400 meters to 3200 meters above sea level. The district comprised of 35 rural and three urban kebeles (Kebele is the smallest administrative unit in Ethiopia). The district is recognized as malaria endemic and fringe zone $[8,19]$. According to the district health office there are malaria cases in the highland fringe localities of the district. The livelihood of most inhabitants of the rural population is mainly subsistence farming.

The KDS-HRC was established in 2007; and it conducts quarterly visit to the households under surveillance to update health and demographic events. The KDS-HRC site includes 12 randomly selected kebeles (10 rural and 2 urban kebeles) of the district. These kebeles were selected based on mix of altitudes and urban-rural composition of the district. In these kebeles, there are 48,244 residents in 10,256 households.

This study was conducted as a baseline survey for a follow up study of consistent and non consistent LLIN user households. Thus, this study reported on a cross sectional survey conducted to determine the household level of LLIN ownership and use. Once the use level was determined; households using LLINs were compared to those who did not use to identify the factors associated with LLINs non-use.

\section{Sample determination and sampling}

A total of 1879 households, 626 LLIN users and 1253 non-users were determined based on the difference between two population proportions with the following assumptions. Based on the study of Baume et al., $67.86 \%$
ITNs use among respondents with correct knowledge on malaria transmission and incorrect knowledge of respondents are expected to use $60.10 \%$ [6], with 95\% confidence level $(Z \alpha / 2)$ and power of the study $80 \%$. However, ITNs ownership among households of malaria endemic areas in the country was $65.6 \%$ [9]. Thus, to obtain 1879 bednet owned households, a total of 2912 households were included in the survey. This sample size was large enough to determine both LLIN ownership and barriers of LLIN use among households.

The study sample was taken from the KDS-HRC database proportional to the size of households of each kebele using simple random sampling. The surveillance database has unique identification number for each household under surveillance. The key informants were women in LLIN owned and non-user households during the time of the survey. The informants were selected purposefully from each of the study kebele of the district using data from the survey and identification number of the households.

\section{Data collection methods}

This survey was conducted after the main rainy season, when the population experience intense mosquito nuisance, which helped to observe and assess mosquito nets use by the residents. A total of 12 experienced and trained female data collectors, who were high school graduates and familiar with the study area; and spoke the local language, were involved. Three experienced female Diploma Nurses have continuously supervised the data collection in the field. A slightly modified Malaria Indicator Survey (MIS) questionnaire that was implemented in Ethiopia in 2007 was used for this study [20]. A qualitative component was integrated into the questionnaire to explore the reasons why some households did not use nets; and observation was used for net use and its conditions. Moreover, a total of 15 in-depth interviews conducted using a semistructured questionnaire. The interviews' questions and discussions focused on reasons of LLIN non-use among LLINs owners. The survey questionnaire contained questions related to socio-economic and demographic status of the households, perception and behaviors about malaria and its control methods, mosquito net ownership and use.

Questionnaire was translated into local language (Oromiffa) and pre-tested before it was administered in faceto face interviews with women of the households. The interviews were conducted during the morning hours. In addition, the data collectors were instructed to make direct observation of the LLINs to verify their condition and where it was placed in the house.

\section{Data analysis}

The data were double entered into EpiData 3.1 by two experienced data operators. Then the data were 
Table 1 Proportion of household by background characteristics in Kersa district, eastern Ethiopia, 2010

\begin{tabular}{|c|c|}
\hline Characteristics & Frequency (\%) \\
\hline \multicolumn{2}{|l|}{ Place of residence $(n=2867)$} \\
\hline Urban & 341 (11.9) \\
\hline Rural & 2526(88.1) \\
\hline \multicolumn{2}{|l|}{ Altitude above sea level } \\
\hline$\leq 2000$ meters & $535(18.7)$ \\
\hline$>2000$ meters & $2332(81.3)$ \\
\hline \multicolumn{2}{|l|}{$\mathrm{HH}$ with children $<5$} \\
\hline Yes & $1644(57.3)$ \\
\hline No & $1223(42.7)$ \\
\hline \multicolumn{2}{|c|}{ Sex of household members $(n=14226)$} \\
\hline Male & $7166(50.4)$ \\
\hline Female & $7060(49.6)$ \\
\hline \multicolumn{2}{|l|}{ Household size } \\
\hline $1-2$ persons & $320(11.2)$ \\
\hline $3-5$ persons & $1444(50.4)$ \\
\hline$>=6$ persons & $1103(38.4)$ \\
\hline \multicolumn{2}{|l|}{ Roof type } \\
\hline Corrugated iron sheet & $2272(79.2)$ \\
\hline Thatched roof and others & $595(20.8)$ \\
\hline \multicolumn{2}{|c|}{ Number of sleeping rooms $(n=2867)$} \\
\hline $1 \mathrm{room}$ & $2481(86.5)$ \\
\hline$\geq 2$ rooms & $386(13.5)$ \\
\hline \multicolumn{2}{|c|}{ IRS sprayed dwellings in last 12 months } \\
\hline Yes & $798(27.8)$ \\
\hline No & $2069(72.2)$ \\
\hline
\end{tabular}

transferred into SPSS 16.0 software. The investigators have cleaned and analysed the data using the same software program. Household ownership of LLIN was calculated as a proportion of households having at least one LLIN among the total surveyed households. LLIN use was estimated as the proportion of households using at least one LLIN in the LLIN owning households. Once the LLIN ownership and use were determined; the data were filtered into a separate file of LLIN owned households. Then households using LLINs were compared to those who did not use to identify the factors associated with LLINs non-use. Barriers of LLIN use were determined by using enter method multivariate logistic regression model. The Omnibus $(\mathrm{P}<0.05)$ and the Hosmer-Lomeshow $(\mathrm{P}>0.05)$ tests were used to check goodness-of-fit of model. Both the open ended questions and in-depth interviews information on non-use of LLIN were coded based on the identified thematic areas.

\section{Ethical considerations}

Ethical clearance was obtained from the Institutional Research Ethics Review Committee of the College of Health Science of Haramaya University. An informed verbal consent was obtained from each study participant prior to conducting the study. The data collectors provided advice to household members who manifested signs and symptoms of malaria during the survey to visit the nearby health facility for diagnosis and treatment.

\section{Results}

\section{Study subject characteristics}

A total of 2867 households and 14226 people were included in the survey. The response rate was $98.5 \%$. Table 1 shows the proportion of selected background characteristics of the surveyed households. Of the total surveyed household members, 16.7\% (2375) were children under five years of age; and among 3165 childbearing aged women, 5.9\% (188) were reported to be pregnant women (Table 2).

\section{LLINs ownership}

Of the surveyed households, $65.5 \%$ (1879) had at least one LLIN while $34.5 \%$ (988) did not have any type of mosquito nets. The majority of LLIN owned households had either one or two LLINs irrespective of their household size. The average LLIN ownership among LLIN owned household was 1.7. Of the total 3137 reported LLINs, 62.4\% (1958) LLINs were observed by the data enumerators. Only $64.2 \%$ (1258) of the total observed LLINs were in good condition, without holes that could allow finger through it. The rest 35.89\% (700) LLINs were in bad conditions, and had holes that allow finger through it. The observation in the survey showed many LLINs were used for covering of household properties. In 1879 LLIN owned households, there were 9629 persons of which $17.1 \%$ (1647) were children under five and $4.6 \%$ (145) were reported to be pregnant women (Table 2). LLIN ownership was significantly higher

Table 2 Proportion of LLINs ownership, its conditions and use among household members in Kersa district, eastern Ethiopia, 2010

\begin{tabular}{lcccc}
\hline & Total Household & Total Population & Children under five & Pregnant women \\
\hline $\mathrm{n}$ & $2867(98.5 \%)$ & 14226 & $2375(16.7 \%)$ & $188(5.9 \%)$ \\
\hline Own at least one LLIN & $1879(65.5 \%)$ & $9629(67.7 \%)$ & $1647(17.1 \%)$ & $145(4.6 \%)$ \\
\hline LLIN in good Conditions & $906(48.2 \%)$ & $4696(48.8 \%)$ & $851(51.7 \%)$ & $82(56.6 \%)$ \\
\hline Slept under LLIN prior night & $630(33.5 \%)$ & $2453(25.5 \%)$ & $767(46.6 \%)$ & $54(37.2 \%)$ \\
\hline
\end{tabular}


Table 3 Factors associated with ownership of at least one LLIN among households, Kersa district, eastern Ethiopia, 2010

\begin{tabular}{|c|c|c|c|c|}
\hline \multirow[t]{3}{*}{ Variables } & \multicolumn{2}{|c|}{ Ownership of at least 1 LLIN } & \multirow{3}{*}{$\begin{array}{c}\text { Crude OR } \\
(95 \% \mathrm{Cl})\end{array}$} & \multirow{3}{*}{$\begin{array}{c}P \\
\text { value }\end{array}$} \\
\hline & \multirow{2}{*}{$\begin{array}{l}\text { Yes } \\
\text { No. (\%) }\end{array}$} & \multirow{2}{*}{$\begin{array}{l}\text { No } \\
\text { No. (\%) }\end{array}$} & & \\
\hline & & & & \\
\hline \multicolumn{5}{|l|}{ Place of residence } \\
\hline Urban & $246(13.1)$ & $95(9.6)$ & $1.42(1.10,1.82)$ & 0.006 \\
\hline Rural & $1633(86.9)$ & $893(90.4)$ & 1 & \\
\hline \multicolumn{5}{|c|}{ Altitude above sea level } \\
\hline$\leq 2000$ meters & $477(25.4)$ & $58(5.9)$ & $5.45(4.10,7.25)$ & 0.001 \\
\hline$>2000$ meters & $1402(74.6)$ & $930(94.1)$ & 1 & \\
\hline \multicolumn{5}{|c|}{$\mathrm{HH}$ with under 5 children } \\
\hline Yes & $1099(58.5)$ & $545(55.2)$ & $1.15(0.98,1.34)$ & 0.087 \\
\hline No & $780(41.5)$ & $443(44.8)$ & 1 & \\
\hline \multicolumn{5}{|l|}{ Household size } \\
\hline $1-2$ persons & $179(9.5)$ & $141(14.3)$ & $0.52(0.41,0.68)$ & 0.001 \\
\hline $3-5$ persons & $919(48.9)$ & $525(53.1)$ & $0.72(0.61,0.85)$ & 0.001 \\
\hline$\geq 6$ persons & $781(41.6)$ & $322(32.6)$ & 1 & \\
\hline \multicolumn{5}{|l|}{ Roof types } \\
\hline $\mathrm{CIS}$ & $1549(82.4)$ & $723(73.2)$ & $1.72(1.43,2.07)$ & 0.001 \\
\hline TR and others & $330(17.6)$ & $265(26.8)$ & 1 & \\
\hline \multicolumn{5}{|c|}{ Number of sleeping rooms } \\
\hline 1 room & $1562(83.1)$ & $919(93.0)$ & $0.37(0.28,0.49)$ & 0.001 \\
\hline$\geq 2$ rooms & $317(16.9)$ & $69(7.0)$ & 1 & \\
\hline \multicolumn{5}{|l|}{ Radio possession } \\
\hline Yes & $692(36.8)$ & $454(45.9)$ & $0.69(0.59,0.80)$ & 0.001 \\
\hline No & $1187(63.2)$ & $534(54.1)$ & 1 & \\
\hline \multicolumn{5}{|c|}{ IRS sprayed in last 12 months } \\
\hline Yes & $662(35.2)$ & $136(13.8)$ & $3.41(2.78,4.18)$ & 0.001 \\
\hline No & $1217(64.8)$ & $852(86.2)$ & 1 & \\
\hline \multicolumn{5}{|l|}{ Malaria preventable } \\
\hline Yes & $1296(69.0)$ & $658(66.6)$ & $0.72(0.58,0.89)$ & 0.002 \\
\hline No & $193(10.3)$ & $188(19.0)$ & $0.37(0.28,0.49)$ & 0.001 \\
\hline I don't know & $390(20.8)$ & $142(14.4)$ & 1 & \\
\hline \multicolumn{5}{|c|}{ Educational status of household head } \\
\hline Illiterate & $1397(74.3)$ & $718(72.7)$ & $0.93(0.73,1.18)$ & 0.567 \\
\hline $1-4$ grades & $240(12.8)$ & $154(15.6)$ & $0.75(0.55,1.01)$ & 0.057 \\
\hline$\geq 5$ grade & $242(12.9)$ & $116(11.7)$ & 1 & \\
\hline \multicolumn{5}{|c|}{ Educational status of household women } \\
\hline Illiterate & $1642(87.4)$ & $844(85.4)$ & $0.90(0.66,1.23)$ & 0.511 \\
\hline $1-4$ grades & $101(5.4)$ & $81(8.2)$ & $0.58(0.38,0.88)$ & 0.010 \\
\hline$\geq 5$ grade & $136(7.2)$ & $63(6.4)$ & 1 & \\
\hline \multicolumn{5}{|c|}{ Highest educational status of household members } \\
\hline Illiterate & $639(34.0)$ & $347(35.1)$ & $0.97(0.81,1.17)$ & 0.770 \\
\hline $1-4$ grades & $570(30.3)$ & $287(29.0)$ & $1.05(0.87,1.27)$ & 0.622 \\
\hline$\geq 5$ grade & $670(35.7)$ & $354(35.9)$ & 1 & \\
\hline
\end{tabular}

Note: $\mathrm{CIS}$, corrugated iron sheet; $\mathrm{HH}$, household; IRS, indoor residual spraying; $n$, study subjects; TR, thatched roof. 
Table 4 Factors associated with LLINs use the night prior to the survey among household members Kersa district, eastern Ethiopia, 2010

\begin{tabular}{|c|c|c|c|c|}
\hline \multirow[t]{2}{*}{ Variables } & \multicolumn{2}{|c|}{ LLINs use } & \multirow[t]{2}{*}{$\operatorname{COR}(95 \% \mathrm{Cl})$} & \multirow[t]{2}{*}{$P$ value } \\
\hline & Users (\%) & Nonusers (\%) & & \\
\hline \multicolumn{5}{|l|}{ Place of residence } \\
\hline Urban & $68(10.8)$ & $178(14.3)$ & $0.73(0.54,0.98)$ & 0.036 \\
\hline Rural & $562(89.2)$ & $1071(85.7)$ & 1 & \\
\hline \multicolumn{5}{|l|}{ Altitude } \\
\hline$\leq 2000 \mathrm{~m}$ & $263(41.7)$ & $214(17.1)$ & $3.47(2.79,4.30)$ & \multirow[t]{2}{*}{0.001} \\
\hline$>2000 \mathrm{~m}$ & $367(58.37)$ & $1035(82.9)$ & 1 & \\
\hline \multicolumn{5}{|c|}{$\mathrm{HH}$ with under 5 children } \\
\hline Yes & $403(64.0)$ & $697(55.8)$ & $1.41(1.16,1.72)$ & \multirow[t]{2}{*}{0.001} \\
\hline No & $227(36.0)$ & $552(44.2)$ & 1 & \\
\hline \multicolumn{5}{|l|}{ Household size } \\
\hline $1-2$ persons & $54(8.6)$ & $125(10.0)$ & $0.84(0.59,1.19)$ & 0.335 \\
\hline $3-5$ persons & $311(49.4)$ & $608(48.7)$ & $0.99(0.81,1.22)$ & 0.969 \\
\hline$\geq 6$ persons & $265(42.1)$ & $516(41.3)$ & 1 & \\
\hline \multicolumn{5}{|l|}{ Education of $\mathrm{HH}$ head } \\
\hline Illiterate & $448(71.1)$ & $949(76.0)$ & $0.75(0.57,1.00)$ & 0.053 \\
\hline $1-4$ grade & $89(14.1)$ & $151(12.1)$ & $0.94(0.65,1.37)$ & 0.760 \\
\hline$\geq 5$ grade & $93(14.8)$ & $149(11.9)$ & 1 & \\
\hline \multicolumn{5}{|l|}{ Education of women } \\
\hline Illiterate & $522(82.9)$ & $1120(89.7)$ & $0.43(0.30,0.61)$ & 0.001 \\
\hline $1-4$ grade & $37(5.9)$ & $64(5.1)$ & $0.53(0.31,0.89)$ & 0.018 \\
\hline$\geq$ ggrade & $71(11.3)$ & $65(5.2)$ & 1 & \\
\hline \multicolumn{5}{|c|}{ Highest education of $\mathrm{HH}$ member } \\
\hline Illiterate & $190(30.1)$ & $449(35.9)$ & $0.89(0.70,1.13)$ & 0.328 \\
\hline $1-4$ grade & $224(35.6)$ & $346(27.7)$ & $1.36(1.08,1.72)$ & 0.010 \\
\hline$\geq$ 5grade & $216(34.3)$ & $454(36.4)$ & 1 & \\
\hline \multicolumn{5}{|l|}{ Sleeping rooms } \\
\hline 1 room & $493(78.3)$ & $1069(85.6)$ & $0.61(0.47,0.77)$ & \multirow[t]{2}{*}{0.001} \\
\hline$\geq 2$ rooms & $137(21.7)$ & $180(14.4)$ & 1 & \\
\hline \multicolumn{5}{|l|}{ Roof types } \\
\hline $\mathrm{CIS}$ & $519(82.4)$ & $1030(82.5)$ & $0.99(0.77,1.28)$ & 0.964 \\
\hline TR and other & $111(17.6)$ & $219(17.5)$ & 1 & \\
\hline \multicolumn{5}{|l|}{ Radio possession } \\
\hline Yes & $229(36.3)$ & $463(37.1)$ & $0.97(0.79,1.18)$ & 0.760 \\
\hline No & $401(63.7)$ & $786(62.9)$ & 1 & \\
\hline \multicolumn{5}{|l|}{ IRS sprayed in last year } \\
\hline Yes & $363(57.6)$ & $299(23.9)$ & $4.32(3.52,5.30)$ & \multirow[t]{2}{*}{0.001} \\
\hline No & $267(42.4)$ & $950(76.1)$ & 1 & \\
\hline \multicolumn{5}{|l|}{ Malaria preventable } \\
\hline Yes & $491(77.9)$ & $805(64.5)$ & $1.79(1.39,2.31)$ & 0.001 \\
\hline No & $40(6.3)$ & $153(12.2)$ & $0.77(0.51,1.16)$ & \multirow[t]{2}{*}{0.215} \\
\hline I don't know & 99 (15.7) & $291(23.3)$ & 1 & \\
\hline \multicolumn{5}{|l|}{ LLINs colour preference } \\
\hline Yes & $136(21.6)$ & $494(39.6)$ & $0.42(0.34,0.52)$ & \multirow[t]{2}{*}{0.001} \\
\hline No & $494(78.4)$ & $755(60.4)$ & 1 & \\
\hline
\end{tabular}


Table 5 Factors associated independently with LLINs use among household members, Kersa district, eastern Ethiopia 2010

\begin{tabular}{|c|c|c|c|c|}
\hline \multirow[t]{2}{*}{ Variables } & \multicolumn{2}{|c|}{ LLINs use } & \multirow[t]{2}{*}{ AOR(95\%Cl) } & \multirow[t]{2}{*}{$P$ value } \\
\hline & Users (\%) & Nonusers (\%) & & \\
\hline \multicolumn{5}{|l|}{ Place of residence } \\
\hline Urban & $68(10.8)$ & $178(14.3)$ & $0.51(0.34,0.76)$ & \multirow[t]{2}{*}{0.001} \\
\hline Rural & $562(89.2)$ & $1071(85.7)$ & & \\
\hline \multicolumn{5}{|l|}{ Altitude } \\
\hline$\leq 2000 \mathrm{~m}$ & $263(41.7 \%)$ & $214(17.1)$ & $2.56(1.99-3.29)$ & \multirow[t]{2}{*}{0.001} \\
\hline$>2000 \mathrm{~m}$ & $367(58.37 \%)$ & 1035 (82.9) & & \\
\hline \multicolumn{5}{|c|}{$\mathrm{HH}$ with under 5 children } \\
\hline Yes & $403(64.0 \%)$ & $697(55.8)$ & $1.36(1.06,1.75)$ & \multirow[t]{2}{*}{0.015} \\
\hline No & $227(36.0 \%)$ & $552(44.2)$ & & \\
\hline \multicolumn{5}{|l|}{ Household size } \\
\hline $1-2$ persons & $54(8.6)$ & $125(10.0)$ & $1.46(0.91,2.35)$ & 0.115 \\
\hline $3-5$ persons & $311(49.4)$ & $608(48.7)$ & $1.27(0.98,1.65)$ & 0.066 \\
\hline$\geq 6$ persons & $265(42.1)$ & $516(41.3)$ & & \\
\hline \multicolumn{5}{|l|}{ Education of $\mathrm{HH}$ head } \\
\hline Illiterate & $448(71.1)$ & $949(76.0)$ & $0.73(0.50,1.07)$ & 0.104 \\
\hline $1-4$ grade & $89(14.1)$ & $151(12.1)$ & $0.67(0.43,1.05)$ & 0.084 \\
\hline$\geq$ 5grade & $93(14.8)$ & $149(11.9)$ & & \\
\hline \multicolumn{5}{|l|}{ Education of women } \\
\hline Illiterate & $522(82.9 \%)$ & $1120(89.7)$ & $0.39(0.24,0.62)$ & 0.001 \\
\hline $1-4$ grade & $37(5.9 \%)$ & $64(5.1 \%)$ & $0.48(0.26,0.89)$ & 0.020 \\
\hline$\geq 5$ grade & $71(11.3 \%)$ & $65(5.2 \%)$ & & \\
\hline \multicolumn{5}{|c|}{ Highest education of $\mathrm{HH}$ member } \\
\hline Illiterate & $190(30.1)$ & $449(35.9)$ & $1.16(0.85,1.57)$ & 0.361 \\
\hline $1-4$ grade & $224(35.6)$ & $346(27.7)$ & $1.63(1.23,2.17)$ & 0.001 \\
\hline$\geq$ 5grade & $216(34.3)$ & $454(36.4)$ & & \\
\hline \multicolumn{5}{|l|}{ Sleeping rooms } \\
\hline $1 \mathrm{room}$ & $493(78.3)$ & 1069 (85.6) & $0.60(0.45,0.74)$ & \multirow[t]{2}{*}{0.001} \\
\hline$\geq 2$ rooms & $137(21.7)$ & $180(14.4)$ & & \\
\hline \multicolumn{5}{|l|}{ Roof types } \\
\hline $\mathrm{CIS}$ & $519(82.4)$ & $1030(82.5)$ & $0.85(0.64,1.15)$ & 0.294 \\
\hline TR and other & $111(17.6)$ & $219(17.5)$ & & \\
\hline \multicolumn{5}{|l|}{ Malaria preventable } \\
\hline Yes & $491(77.9)$ & $805(64.5)$ & $1.09(0.83,1.45)$ & 0.526 \\
\hline No & $40(6.3)$ & $153(12.2)$ & $0.43(0.27,0.68)$ & 0.001 \\
\hline I don't know & $99(15.7)$ & $291(23.3)$ & & \\
\hline \multicolumn{5}{|l|}{ LLINs colour preference } \\
\hline Yes & $136(21.6)$ & $494(39.6)$ & $0.41(0.31,0.53)$ & \multirow[t]{2}{*}{0.001} \\
\hline No & $494(78.4)$ & $755(60.4)$ & & \\
\hline \multicolumn{5}{|l|}{ Number of LLINs } \\
\hline 1 LLIN & $223(35.4)$ & $565(46.0)$ & $0.25(0.17,0.39)$ & 0.001 \\
\hline 2 LLINS & $309(49.0)$ & $611(49.7)$ & $0.36(0.25,0.54)$ & 0.001 \\
\hline$\geq 3$ LLINS & $98(15.6)$ & $53(4.3)$ & & \\
\hline
\end{tabular}


household, even if the net was available in the house and in hanged position. This may not be a problem at least to ensure use of at least one LLIN at least by one of the household members, including the young children and the respondent herself. In addition, the presence of hanged LLIN above the bed or sleeping place in the room was considered as a proxy indicator to LLIN use. The study also relied on a cross sectional survey conducted after the main rainy season when mosquito density and malaria transmission is high which LLIN use may be more likely to be higher than during the dry season. But, it may be useful for understanding of the reasons why LLIN owned households did not use it.

Though the women's awareness on malaria prevention was moderate $(68.2 \%)$, it was not translated into LLIN use in the study area, which is consistent with the other study in the country [16]. Similarly, several cross sectional studies have shown that women in some African countries have reasonably good knowledge on the cause and prevention of malaria. However, the extent of mosquito net use is not as good as their knowledge [25,26]. It may be due to the differences on the burden of mosquito bite and malaria infection and access to health information [26].

More urban households $(72.1 \%)$ owned LLINs than rural $(64.6 \%)$ ones $(\mathrm{COR}=1.42,95 \% \mathrm{CI} 1.10,1.82)$. This is lower than Kafta-Humera district, Ethiopia where the study reported $91.1 \%$ in urban and $80.0 \%$ in rural households [27]. But higher than the 2007 MIS report, 39.5\% of urban and $56.2 \%$ rural [9]. When the confounding factors are controlled, LLIN use was lower in urban $(27.6 \%)$ than rural (34.4\%) households (Adjusted $\mathrm{OR}=0.51 ; 95 \% \mathrm{CI}, 0.34,0.76)$. This is in contrary with Haileselassie et al. and the 2007 MIS survey reports, though both studies assessed ITNs use among selected household members only. There would be a couple of explanations for this difference: difference in housing construction and use, like using a separate room for cooking, presence of separate bed rooms, and expansion of health extension program in the rural part of the country could be among the reasons. The LLINs use was higher among residents of malaria endemic zone than fringe zone residents, and this is consistent with other studies in the country $[6,9]$. This may be attributed to low mosquito population and malaria infections in the malaria fringe zone than the malaria endemic areas. It would also be more likely that health extension workers may give more messages on malaria prevention and control methods and LLIN use to malaria endemic area residents.

Absence of separate sleeping room, sharing rooms with domestic animals and putting fire place in the room were household barriers to LLIN use. This is similar with a cross sectional study conducted in the country
[16]. Sharing of one common sleeping place in the house may not be convenient to use LLIN for all of the household members. Observation also showed that most rural residents had non partitioned single room and had a fire place in the same room which may not be convenient to hang LLINs regularly. However, the sleeping habit of the community favoured the young children to share the available LLIN with their mother or father. LLIN ownership was not different between households that had children under five years $(66.8 \%)$ and those did not have $(63.8 \%)$. This is may be due to the universal target to LLINs coverage to all malaria risk residents. However, the presence of young children in the household and living in recognized endemic zone were independent predictors of LLIN use (Table 5).

The study also identified that LLINs colour and shape preference were barriers to bednets use. The blue and cylindrical shape LLINs were more preferable than the white and rectangular. The study also showed that the majority (91.8\%) of the households had either one or two LLINs, which may be inadequate to use for big household members.

The qualitative part of the study also supported that hanging of rectangular net is inconvenient and hard to keep for a long time in hanged position in small multipurpose room. It was also mentioned that the white nets may be coated or soiled with soot and may be unsightly to use for a long time. Recent studies in Ethiopia $[6,16]$ and in Kenya [28] have also demonstrated that ITNs size, shape, colour and the availability of ITNs in the household as the barriers to mosquito nets use. The qualitative open ended questions and the observations showed that several LLINs were in a poor condition and handled improperly. Some households had used LLINs to cover some household properties which may shorten the service years of the LLINs and may make the nets conditions poor.

\section{Conclusions}

Although LLINs ownership was moderate, only a small proportion of the household members slept under LLINs in previous night of the survey. Thus, residents are at higher risk of mosquito bite and acquiring of malaria infection. This study also revealed the barriers of LLIN use. These barriers can be categorized under individual, household, socio-economic, LLIN and environmental related factors. Further progress in malaria prevention can be achieved by specifically targeting populations in malaria fringe zones and conducting focused public education to increase use of mosquito net.

Competing interests

The authors declare that they have no competing interests. 


\section{Authors' contributions}

All authors were involved in all steps from design of the research to write up of the paper. All have read and approved the paper.

\section{Acknowledgements}

The study was funded by Haramaya University. We would like to thank data collectors, field supervisors and all the respondents who participated in the study. We also thank Balcha A. for his support in editing the final manuscript.

\section{Author details}

${ }^{1}$ College of Health Sciences, Haramaya University, Harar, P.O. Box: 235 Ethiopia. ${ }^{2}$ Addis Continental Institute of Public Health, Addis Ababa, Ethiopia. ${ }^{3}$ School of Public Health, Addis Ababa University, Addis Ababa, Ethiopia.

Received: 18 May 2012 Accepted: 16 October 2012

Published: 29 October 2012

\section{References}

1. Roll Back Malaria: Global strategic plan 2005-2015. 2005. http://www. rollbackmalaria.org/forumV/docs/gsp_en.pdf. Roll Back Malaria Partnership Secretariat, Geneva, Switzerland.

2. Larsen DA, Keating J, Miller J, Bennett A, Changufu C, Katebe C, Eisele TP: Barriers to insecticide-treated mosquito Net possession 2 years after a mass free distribution campaign in Luangwa district, Zambia. PLoS One 2010, 5:e13129. doi:10.1371/journal.pone.00131295.

3. Monasch R, Reinisch A, Steketee RW, Korenromp EL, Alnwick D, Bergevin Y: Child coverage with mosquito nets and malaria treatment from population based surveys in African countries: a baseline for monitoring progress in RBM. Trop Med Hyg 2004, 71:232-238.

4. Baume CA, Marin MC: Gains in awareness, ownership and use of insecticide-treated nets in Nigeria, Senegal Uganda and Zambia. Malaria Journal 2008, 7:153.

5. Haileselassie B, Ali A: Assessment of insecticide treayed nets coverage for malaria control in Kafta-Humera district, Tigray: Possession versus use by high-risk groups. Ethiop J Health Dev 2008, 22:259-267.

6. Baume CA, Reithinge $R$, Woldehanna S: Factors associated with use and non-use of mosquito nets owned in Oromia and Amhara Regional States Ethiopia. Malaria Journal 2009, 8:264.

7. Federal Democratic Republic of Ethiopia, Ministry of Heallth: National fiveyear strategic plan for malaria prevention and control in Ethiopia 2006-2010. Addis Ababa, Ethiopia: Federal Ministry of Health; 2006.

8. Central Statistical Authority (Ethiopia) ORC macro: Ethiopia demographic and health survey 2005. Addis Ababa, Ethiopia and Calverton 2006: Central Statistical Agency and ORC Macro; 2006.

9. Federal Democratic Republic of Ethiopia, Ministry of Heallth: Ethiopia national malaria indicator survey 2007. Addis Ababa, Ethiopia: Federal Ministry of Health (Ethiopia); 2008.

10. Fegan GW, Noor AM, Akhwale WSCS, Snow RW: Effect of expanded insecticide-treated bednet coverage on child survival in rural Kenya: a longitudinal study. Lancet 2007, 370:1035-1039.

11. Lim SS, Fullman N, Stokes A, Ravishankar N, Masiye F, Murray CJL, Gakidou E: Net benefits: a multicountry analysis of observational data examining associations between insecticide-treated mosquito nets and health outcomes. PLoS Med 2011, 8:e1001091. doi:1001010.1001371/journal. pmed.1001091.

12. Eisele TP, Keating J, Littrell M, Larsen D, Macintyre K: Assessment of insecticide-treated bednet Use among children and pregnant women across 15 countries using standardized national surveys. Am J Trop Med Hyg 2009, 80:209-214.

13. Toé LP, Skovmand O, Dabiré KR, Diabaté A, Diallo Y, Guiguemdé TR, Marie J, Doannio C, Akogbeto M, Baldet T, Gruénais M: Decreasing motivation in the use of insecticide-treated nets in a malaria endemic area in Burkina Faso. Malar J 2009, 8:175

14. Frey C, Traoré C, Allegri MD, Kouyaté B, Müller O: Compliance of young children with ITN protection in rural Burkina Faso. Malar J 2006, 5:70.

15. Deribew A, Alemseged F, Birhanu Z, Sena L, Tegegn A, Zeynudin A, Dejene T, Sudhakar M, Abdo N, Tessem F: Effect of training on the use of longlasting insecticide-treated bed nets on the burden of malaria among vulnerable groups, south-west Ethiopia: baseline results of a cluster randomized trial. Malar J 2010, 9:121.
16. Dagne G, Deressa W: Knowledge and utilization of insecticide treated mosquito nets among freely supplied households in wonago woreda, southern Ethiopia. Ethiop J Health Dev 2008, 22:34-41.

17. Pulford J, Hetzel MW, Bryant M, Siba PM, Mueller I: Reported reasons for not using a mosquito net when one is available: a review of the published literature. Malar J 2011, 10:83.

18. Federal Democratic Republic of Ethiopia Ministry of Heallth: Entomological profile of malaria in Ethiopia. Addis Ababa, Ethiopia: World Health Organization; 2007

19. Central Statistical Agency (Ethiopia): The 2007 population and housing census of Ethiopia: statistical report for oromia region. Addis Ababa, Ethiopia: Central Statistical Agency; 2008.

20. World Health Organization: Roll back malaria monitoring and evaluation reference group: malaria indicator survey:basic documentation for survey design and implementation. Calverton, Maryland: ORC Macro; 2005.

21. Noor AM, Mutheu JJ, Tatem AJ, Hay SI, Snow RW: Insecticide-treated net coverage in Africa: mapping progress in 2000-07. Lancet 2009, 373:58-67.

22. Baume CA, Marin MC: Intra-household mosquito net use in Ethiopia, Ghana, Mali, Nigeria, Senegal, and Zambia: Are nets being used? Who in the household uses them? Am J Trop Med Hyg 2007, 77:963-971.

23. United Nations Children's Fund/Roll Back Malaria Partnership: Malaria and children: progress in intervention coverage. New York: United Nations Children's Fund; 2007. http://www.unicef.org/health/files/ Malaria_Oct6_for_web(1)pdf Accessed September 12, 2012.

24. Graves PM, Richards FO, Ngondi J, Emerson PM, Shargie EB, Endeshaw T, Ceccato P, Ejigsemahu Y, Mosher AW, Hailemariam A, et al: Individual, household and environmental risk factors for malaria infection in amhara, oromia and SNNP regions of Ethiopia. Trans $R$ Soc Trop Med Hyg 2009, 103:1211-1220.

25. Mbonye AK, Neema S, Magnussen P: Preventing malaria in pregnancy: a study of perceptions and policy implications in mukono district, Uganda. Health Policy Plan 2006, 21:17-26.

26. Oresanya OB, Hoshen M, Sofola OT: Utilization of insecticide-treated nets by under-five children in Nigeria: assessing progress towards the Abuja targets. Malar J 2008, 7:145.

27. Haileselassie B, Ali A: Assessment of insecticide treated nets coverage from malaria control in kafta-humera district, tigray: possession versus use by high risk groups. Ethiopia Journal of Health and Development 2008, 22:259-267.

28. Chuma J, Okungu V, Ntwiga J, Molyneux C: Achieving Abuja targets: identifying and addressing barriers to access and use of insecticides treated nets among the poorest populations in Kenya. BMC Public Health 2010, 10:137.

\section{doi:10.1186/1471-2458-12-914}

Cite this article as: Gobena et al.: Low long-lasting insecticide nets (LLINs) use among household members for protection against mosquito bite in kersa, Eastern Ethiopia. BMC Public Health 2012 12:914.

\section{Submit your next manuscript to BioMed Central and take full advantage of:}

- Convenient online submission

- Thorough peer review

- No space constraints or color figure charges

- Immediate publication on acceptance

- Inclusion in PubMed, CAS, Scopus and Google Scholar

- Research which is freely available for redistribution 